ORIGINAL ARTICLE

\section{General and Abdominal Adiposity and Risk of Death in Europe}

\author{
T. Pischon, M.D., M.P.H., H. Boeing, Ph.D., M.S.P.H., K. Hoffmann, Ph.D.,** \\ M. Bergmann, Ph.D., M.B. Schulze, Dr.P.H., K. Overvad, M.D., Ph.D., \\ Y.T. van der Schouw, Ph.D., E. Spencer, Ph.D., K.G.M. Moons, Ph.D., \\ A. Tjønneland, M.D., Ph.D., Dr.Med.Sci., J. Halkjaer, Ph.D., M.K. Jensen, Ph.D., \\ J. Stegger, M.D., F. Clavel-Chapelon, Ph.D., M.-C. Boutron-Ruault, Ph.D., \\ V. Chajes, Ph.D., J. Linseisen, Ph.D., R. Kaaks, Ph.D., A. Trichopoulou, M.D., Ph.D., \\ D. Trichopoulos, M.D., Ph.D., C. Bamia, Ph.D., S. Sieri, Ph.D., D. Palli, M.D., \\ R. Tumino, M.D., P. Vineis, M.D., M.P.H., S. Panico, M.D., M.Sc., \\ P.H.M. Peeters, M.D., Ph.D., A.M. May, Ph.D., \\ H.B. Bueno-de-Mesquita, M.D., Ph.D., M.P.H., F.J.B. van Duijnhoven, Ph.D., \\ G. Hallmans, M.D., L. Weinehall, M.D., Ph.D., J. Manjer, M.D., Ph.D., \\ B. Hedblad, M.D., Ph.D., E. Lund, M.D., Ph.D., A. Agudo, Ph.D., L. Arriola, Ph.D., \\ A. Barricarte, Ph.D., C. Navarro, M.D., Ph.D., C. Martinez, M.D., J.R. Quirós, M.D., \\ T. Key, D.Phil., S. Bingham, Ph.D., K.T. Khaw, M.B., B.Chir., P. Boffetta, M.D., M.P.H., \\ M. Jenab, Ph.D., P. Ferrari, Ph.D., and E. Riboli, M.D., M.P.H., Sc.M.
}

\section{A BSTRACT}

\section{BACKGROUND}

Previous studies have relied predominantly on the body-mass index (BMI, the weight in kilograms divided by the square of the height in meters) to assess the association of adiposity with the risk of death, but few have examined whether the distribution of body fat contributes to the prediction of death.

\section{METHODS}

We examined the association of BMI, waist circumference, and waist-to-hip ratio with the risk of death among 359,387 participants from nine countries in the European Prospective Investigation into Cancer and Nutrition (EPIC). We used a Cox regression analysis, with age as the time variable, and stratified the models according to study center and age at recruitment, with further adjustment for educational level, smoking status, alcohol consumption, physical activity, and height.

\section{RESULTS}

During a mean follow-up of 9.7 years, 14,723 participants died. The lowest risks of death related to BMI were observed at a BMI of 25.3 for men and 24.3 for women. After adjustment for BMI, waist circumference and waist-to-hip ratio were strongly associated with the risk of death. Relative risks among men and women in the highest quintile of waist circumference were 2.05 (95\% confidence interval [CI], 1.80 to 2.33) and 1.78 (95\% CI, 1.56 to 2.04), respectively, and in the highest quintile of waist-tohip ratio, the relative risks were 1.68 ( $95 \%$ CI, 1.53 to 1.84) and 1.51 (95\% CI, 1.37 to 1.66), respectively. BMI remained significantly associated with the risk of death in models that included waist circumference or waist-to-hip ratio $(\mathrm{P}<0.001)$.

CONCLUSIONS

These data suggest that both general adiposity and abdominal adiposity are associated with the risk of death and support the use of waist circumference or waist-tohip ratio in addition to BMI in assessing the risk of death.
The authors' affiliations are listed in the Appendix. Address reprint requests to Dr. Tobias Pischon at the Department of Epidemiology, German Institute of Human Nutrition, Potsdam-Rehbruecke, ArthurScheunert-Allee 114-116, 14558 Nuthetal, Germany, or at pischon@dife.de.

*Deceased.

This article (10.1056/NEJMoa0801891) was updated on June 23, 2010, at NEJM.org.

N Engl J Med 2008;359:2105-20. Copyright (๑) 2008 Massachusetts Medical Society. 
BDOMINAL OBESITY IS MORE CLOSELY associated with the risk of several chronic diseases than is gluteofemoral obesity, and large studies have suggested that waist circumference or the waist-to-hip ratio, as indicators of abdominal obesity, may be better predictors of the risk of disease than the body-mass index (BMI, the weight in kilograms divided by the square of the height in meters), an indicator of general adiposity. ${ }^{1-4}$ Current guidelines with respect to obesity recommend the measurement of waist circumference in persons with a BMI between 25.0 and 34.9 and propose cutoff points for waist circumference of $102 \mathrm{~cm}$ in men and 88 $\mathrm{cm}$ in women (and cutoff points for waist-to-hip ratio of 1.0 in men and 0.85 in women) to define abdominal obesity and to identify persons at risk for disease. ${ }^{2}$ However, less is known about the association of waist circumference or waist-to-hip ratio with the risk of death.

Most studies that have examined the association of both general and abdominal obesity with the risk of death ${ }^{5-16}$ have shown that abdominal adiposity is an important predictor of the risk of death, but few such studies were conducted in Europe. ${ }^{14-16}$ Large studies in the United States and Korea either did not assess waist circumference or waist-to-hip ratio ${ }^{17,18}$ or relied on selfreports of anthropometric measurements. ${ }^{12,19} \mathrm{We}$ therefore evaluated the association of general and abdominal adiposity with the risk of death in the European Prospective Investigation into Cancer and Nutrition (EPIC), a large cohort study in Europe.

\section{METHODS}

\section{STUDY POPULATION}

EPIC includes 519,978 men and women who were 25 to 70 years of age at enrollment (during the period from 1992 through 2000) and who were recruited predominantly from the general population residing in a given geographic area (town or province) in 23 centers in 10 European countries (Denmark, France, Germany, Greece, Italy, the Netherlands, Norway, Spain, Sweden, and the United Kingdom) (see Table 1 of the Supplementary Appendix, available with the full text of this article at www.nejm.org). ${ }^{20}$ Participants gave written informed consent, underwent anthropometric measurements, and completed a questionnaire that asked for information regarding sociodemographic and lifestyle characteristics, medical histo- ry, alcohol consumption, and physical activity. ${ }^{20-22}$ Approval was obtained from the ethics review board of the International Agency for Research on Cancer and the local review boards of the participating institutions. The association of anthropometric measures with the risk of death has previously been reported in two cohorts that are part of EPIC - those in Denmark and Malmö, Sweden. ${ }^{15,16}$ These participants are included in the present analysis with longer follow-up periods.

We excluded 2088 participants who withdrew from the study and for whom there was no followup information on vital status. Furthermore, the cohort in Umeå, Sweden (25,720 persons), was excluded because the information on leisure-time physical activity provided on the questionnaire completed by this cohort was not compatible with that provided on the other EPIC questionnaires. We also excluded subjects for whom data on measured height or weight were missing - all the participants from the Norwegian cohorts (37,205 persons), 52,872 participants from the French cohorts, and 8451 from other cohorts. In addition, we excluded 1441 participants with missing questionnaire data and, to reduce the effect of implausible extreme values, 7659 participants who were in the top or bottom $1 \%$ of the total cohort with respect to the ratio of energy intake to estimated energy requirement. ${ }^{23}$ Finally, to avoid confounding by preexisting chronic diseases, we excluded 25,155 participants who reported a history of cancer, heart disease, or stroke at baseline. Thus, the final study included 359,387 participants.

\section{ASSESSMENT OF END POINTS}

Vital status and the cause and date of death were ascertained by means of record linkages with cancer registries, boards of health, and death indexes (in the case of Denmark, Italy, the Netherlands, Spain, Sweden, and the United Kingdom) or by active follow-up (in the case of Germany, Greece, and France). Active follow-up included inquiries by mail or telephone to participants, municipal registries, regional health departments, physicians, and hospitals. Data on death were coded according to the rules of the International Classification of Diseases, 10th Revision (ICD-10). The code for the underlying cause of death was used, classified as circulatory (ICD-10 codes I00 through I99), neoplasms (C00 through D48), respiratory (J00 through J99 [i.e., not including neoplasms of the respiratory organs]), other, or not reported. 


\section{ASSESSMENT OF ANTHROPOMETRIC DATA}

Weight and height were measured with subjects not wearing shoes. ${ }^{24}$ Waist circumference was measured either at the narrowest circumference of the torso or at the midpoint between the lower ribs and the iliac crest. Hip circumference was measured horizontally at the level of the largest lateral extension of the hips or over the buttocks. Each participant's body weight and waist and hip circumferences were corrected for the clothing worn during measurement in order to reduce heterogeneity due to protocol differences among centers (see Appendix 1 in the Supplementary Appendix for a detailed description). Measurements of waist circumference and waist-to-hip ratio were missing for 3833 participants (1.07\%) and 6466 participants $(1.80 \%)$, respectively. These participants were excluded from analyses of these variables.

\section{STATISTICAL ANALYSIS}

Associations between anthropometric variables and the risk of death were analyzed with the use of a Cox regression model, with age as the underlying time variable. We divided the cohort into categories of BMI that were similar to those used for the National Institutes of Health-AARP cohort ( $<18.5,18.5$ to $<21.0,21.0$ to $<23.5,23.5$ to $<25.0$, 25.0 to $<26.5,26.5$ to $<28.0,28.0$ to $<30.0,30.0$ to $\left\langle 35.0\right.$, and $\geq 35.0$ ). ${ }^{17}$ These categories incorporate current definitions of underweight (BMI, $<18.5$ ), normal weight (18.5 to $<25.0$ ), overweight (25.0 to $<30.0)$, and obesity $(\geq 30.0){ }^{2}$ The likelihood-ratio test was used to assess the statistical significance of an asssociation between BMI and the risk of death. In addition, subjects were grouped into sex-specific quintiles according to waist circumference and waist-to-hip ratio. Tests for trend in relative risks were based on medians across quintiles. The relationships were also evaluated with the use of nonparametric restricted cubic splines, ${ }^{25}$ with 4 knots defined at the 5th, 25th, 75th, and 95th percentiles of the anthropometric measurements. All models were stratified according to age at recruitment and according to study center to reduce violations of the proportional-hazards assumption. The analysis was further adjusted for smoking status, educational level, alcohol consumption, physical activity, and height. Models for waist circumference and waist-to-hip ratio were also adjusted for BMI.

Subgroup analyses were conducted according to strata of smoking status and age at recruit- ment. Waist circumference and waist-to-hip ratio were also examined across sex-specific BMI thirds. Tests for interaction were performed with the likelihood-ratio test of models with and without interaction terms. Differences according to the cause of death were examined in competing risk models. ${ }^{26}$ Similar analyses examined differences between models that censored follow-up time after 5 years and models that excluded persontime and events from the first 5 years.

To assess performance in the prediction of death, we calculated the $\mathrm{C}$ statistic, the HosmerLemeshow statistic, Nagelkerke's generalizedmodel $\mathrm{R}^{2}$ statistic, and net reclassification indexes for a follow-up time of 5 years (available for $98.2 \%$ of the cohort), using logistic-regression models, adjusted for the covariates described above. ${ }^{27-31}$

All $\mathrm{P}$ values presented are two-tailed, and $P$ values of less than 0.05 were considered to indicate statistical significance. Analyses were performed with the use of SAS software, version 9.1 (SAS Institute).

\section{RESULTS}

\section{CHARACTERISTICS OF STUDY PARTICIPANTS}

During a mean $( \pm S D)$ follow-up of $9.7 \pm 2.0$ years, 14,723 of the initial 359,387 participants died (5429 from neoplasms, 3443 from circulatory causes, 637 from respiratory causes, 2209 from other causes, and 3005 from unspecified causes; see Table 1 in the Supplementary Appendix). The mean age at baseline was $51.5 \pm 10.4$ years; $65.4 \%$ of the participants were women. Participants with a higher BMI, as compared with those who had a lower BMI, were older, were less likely to be current smokers, and had a lower educational level (see Table 2 in the Supplementary Appendix). Alcohol consumption was positively related to BMI among men but inversely related to BMI among women. Pearson partial-correlation coefficients, adjusted for age and study center, for the correlation of BMI with waist circumference and with waist-to-hip ratio were 0.85 and 0.55 , respectively, among men and 0.84 and 0.38 , respectively, among women $(\mathrm{P}<0.001$ for all correlations).

\section{ASSOCIATIONS WITH THE RISK OF DEATH}

There was a significant nonlinear association of BMI with the risk of death, with the lowest risks at a BMI of 25.3 among men and 24.3 among women, and increased risks in the lower and upper BMI categories (Table 1 and Fig. 1). These 


\begin{tabular}{|c|c|c|c|c|c|}
\hline \multirow[t]{2}{*}{ Relative Risk } & \multicolumn{5}{|c|}{ BMI } \\
\hline & $<18.5$ & 18.5 to $<21.0$ & 21.0 to $<23.5$ & 23.5 to $<25.0$ & 25.0 to $<26.5$ \\
\hline Person-years & 4504 & 45,494 & 176,701 & 188,823 & 215,370 \\
\hline Deaths (no.) & 92 & 390 & 1071 & 1144 & 1209 \\
\hline \multicolumn{6}{|c|}{ Overall relative risk $(95 \% \mathrm{Cl})$} \\
\hline Crude $\mathbb{1}$ & $2.86(2.30-3.57)$ & $1.64(1.46-1.84)$ & $1.08(0.99-1.17)$ & 1.00 & $0.90(0.83-0.98)$ \\
\hline Adjusted & $2.30(1.84-2.86)$ & $1.39(1.24-1.57)$ & $1.03(0.94-1.12)$ & 1.00 & $0.91(0.84-0.99)$ \\
\hline \multicolumn{6}{|c|}{ Relative risk by subgroup $(95 \% \mathrm{Cl})$} \\
\hline \multicolumn{6}{|c|}{ Smoking status $\|$} \\
\hline Never smoked & $1.19(0.54-2.62)$ & $1.25(0.93-1.67)$ & $0.97(0.80-1.07)$ & 1.00 & $0.89(0.73-1.07)$ \\
\hline Former smoker & $2.18(1.39-3.41)$ & $1.69(1.34-2.13)$ & $1.05(0.90-1.22)$ & 1.00 & 0.95 (0.83-1.09) \\
\hline Current smoker & $2.75(2.09-3.63)$ & $1.39(1.19-1.63)$ & $1.03(0.91-1.17)$ & 1.00 & $0.86(0.76-0.98)$ \\
\hline \multicolumn{6}{|l|}{ Age } \\
\hline$<55 \mathrm{yr}$ & $4.43(3.01-6.54)$ & $1.66(1.33-2.07)$ & $1.07(0.90-1.26)$ & 1.00 & $1.09(0.93-1.28)$ \\
\hline 55 to $<65 \mathrm{yr}$ & $2.27(1.55-3.33)$ & $1.30(1.09-1.55)$ & $1.03(0.91-1.17)$ & 1.00 & $0.83(0.73-0.93)$ \\
\hline$\geq 65 \mathrm{yr}$ & $1.56(1.07-2.27)$ & $1.32(1.06-1.65)$ & $1.00(0.85-1.17)$ & 1.00 & $0.91(0.77-1.06)$ \\
\hline \multicolumn{6}{|l|}{ Follow-up } \\
\hline$\leq 5 \mathrm{yr}$ & $3.08(2.26-4.20)$ & $1.29(1.06-1.57)$ & $1.02(0.89-1.17)$ & 1.00 & $0.84(0.73-0.96)$ \\
\hline$>5 \mathrm{yr}$ & $1.78(1.30-2.45)$ & $1.45(1.25-1.68)$ & $1.03(0.93-1.15)$ & 1.00 & $0.95(0.86-1.05)$ \\
\hline \multicolumn{6}{|l|}{ Cause of death } \\
\hline Neoplasms & $1.20(0.73-1.97)$ & $1.27(1.03-1.55)$ & $0.92(0.80-1.07)$ & 1.00 & $0.82(0.72-0.95)$ \\
\hline Circulatory & 1.84 (1.19-2.87) & $1.05(0.81-1.36)$ & $0.97(0.81-1.15)$ & 1.00 & $0.95(0.80-1.12)$ \\
\hline Respiratory & $6.53(3.56-11.97)$ & $2.29(1.46-3.59)$ & $1.21(0.84-1.76)$ & 1.00 & $0.66(0.44-0.99)$ \\
\hline Other & $4.67(2.98-7.31)$ & $2.02(1.54-2.66)$ & $1.30(1.05-1.60)$ & 1.00 & $0.99(0.80-1.22)$ \\
\hline \multicolumn{6}{|l|}{ Women } \\
\hline Person-years & 41,623 & 286,794 & 574,777 & 344,116 & 287,155 \\
\hline Deaths (no.) & 167 & 714 & 1397 & 953 & 865 \\
\hline \multicolumn{6}{|c|}{ Overall relative risk $(95 \% \mathrm{Cl})$} \\
\hline Cruded & $1.96(1.66-2.32)$ & $1.27(1.15-1.40)$ & $1.01(0.93-1.10)$ & 1.00 & $1.01(0.92-1.11)$ \\
\hline Adjusted $\emptyset$ & $1.71(1.44-2.01)$ & $1.22(1.10-1.34)$ & $1.00(0.92-1.09)$ & 1.00 & $1.01(0.92-1.11)$ \\
\hline \multicolumn{6}{|c|}{ Relative risk by subgroup $(95 \% \mathrm{Cl}) \emptyset$} \\
\hline \multicolumn{6}{|c|}{ Smoking status $\|$} \\
\hline Never smoked & $1.44(1.08-1.92)$ & $1.09(0.93-1.27)$ & $1.00(0.88-1.13)$ & 1.00 & $1.00(0.87-1.15)$ \\
\hline Former smoker & $1.47(0.98-2.20)$ & $1.01(0.82-1.25)$ & $0.85(0.72-1.00)$ & 1.00 & $0.94(0.79-1.12)$ \\
\hline Current smoker & $2.29(1.79-2.95)$ & $1.53(1.29-1.81)$ & $1.14(0.98-1.33)$ & 1.00 & $1.07(0.90-1.28)$ \\
\hline \multicolumn{6}{|l|}{ Age } \\
\hline$<55 \mathrm{yr}$ & $1.69(1.26-2.27)$ & $1.15(0.97-1.37)$ & $0.96(0.82-1.11)$ & 1.00 & $1.04(0.87-1.25)$ \\
\hline 55 to $<65 \mathrm{yr}$ & $1.92(1.49-2.48)$ & $1.26(1.08-1.47)$ & $1.01(0.89-1.15)$ & 1.00 & $0.97(0.84-1.12)$ \\
\hline$\geq 65 \mathrm{yr}$ & $1.40(1.01-1.96)$ & $1.28(1.05-1.56)$ & $1.04(0.89-1.23)$ & 1.00 & $1.04(0.87-1.24)$ \\
\hline \multicolumn{6}{|l|}{ Follow-up ** } \\
\hline$\leq 5 \mathrm{yr}$ & $2.01(1.51-2.68)$ & $1.17(0.97-1.40)$ & $1.07(0.92-1.24)$ & 1.00 & $0.99(0.84-1.16)$ \\
\hline$>5 \mathrm{yr}$ & $1.56(1.27-1.92)$ & $1.24(1.10-1.40)$ & $0.97(0.88-1.08)$ & 1.00 & $1.02(0.91-1.14)$ \\
\hline \multicolumn{6}{|l|}{ Cause of death } \\
\hline Neoplasms & $1.16(0.85-1.58)$ & $1.17(1.00-1.36)$ & $0.98(0.86-1.11)$ & 1.00 & $1.00(0.87-1.15)$ \\
\hline Circulatory & $1.09(0.69-1.75)$ & $1.10(0.87-1.41)$ & $1.01(0.83-1.22)$ & 1.00 & $1.13(0.92-1.39)$ \\
\hline Respiratory & $4.74(2.60-8.64)$ & $1.70(1.05-2.76)$ & $1.29(0.85-1.97)$ & 1.00 & $0.64(0.37-1.11)$ \\
\hline Other & $2.97(2.07-4.27)$ & $1.43(1.10-1.84)$ & $1.11(0.89-1.39)$ & 1.00 & $1.02(0.79-1.31)$ \\
\hline
\end{tabular}

* BMI denotes body-mass index, which is the weight in kilograms divided by the square of the height in meters. $\mathrm{Cl}$ denotes confidence interval.

$\dagger \mathrm{P}$ values, based on the likelihood-ratio test, are for comparisons of the model that included BMI categories with the model that did not include BMI categories, with 8 degrees of freedom.

$\ddagger \quad$ Palues, based on the likelihood-ratio test, are for comparisons of the model that included interaction terms between BMI and the stratification variable with the model that did not include these interaction terms (with 16 degrees of freedom each for smoking status and age, 24 degrees of freedom for cause of death, and 8 degrees of freedom each for preexisting disease and length of follow-up); for cause of death and length of follow-up, the data-augmentation method described by Lunn and McNeil was used. ${ }^{26}$

$\int$ The crude relative risk was calculated with the use of Cox proportional-hazards regression, with age as the underlying time variable and stratification according to center and age at recruitment. 


\begin{tabular}{|c|c|c|c|c|c|}
\hline \multicolumn{4}{|c|}{ BMI } & \multirow[t]{2}{*}{ P Value' } & \multirow[t]{2}{*}{ P Value for Interaction } \\
\hline 26.5 to $<28.0$ & 28.0 to $<30.0$ & 30.0 to $<35.0$ & $\geq 35.0$ & & \\
\hline 186,758 & 177,458 & 157,899 & 24,794 & & \\
\hline 1118 & 1212 & 1256 & 313 & & \\
\hline $0.95(0.88-1.03)$ & $1.09(1.01-1.18)$ & $1.28(1.18-1.39)$ & $2.06(1.81-2.34)$ & $<0.001$ & \\
\hline \multirow[t]{2}{*}{$0.96(0.88-1.04)$} & $1.08(1.00-1.17)$ & $1.24(1.14-1.35)$ & $1.94(1.71-2.20)$ & $<0.001$ & \\
\hline & & & & & 0.09 \\
\hline $1.05(0.86-1.27)$ & $1.21(1.01-1.47)$ & $1.48(1.22-1.79)$ & $2.78(2.09-3.71)$ & $<0.001$ & \\
\hline $1.01(0.88-1.15)$ & $1.16(1.01-1.32)$ & $1.39(1.21-1.59)$ & $2.10(1.71-2.58)$ & $<0.001$ & \\
\hline \multirow[t]{2}{*}{$0.91(0.80-1.03)$} & $0.99(0.87-1.13)$ & $1.11(0.98-1.26)$ & $1.66(1.34-2.05)$ & $<0.001$ & \\
\hline & & & & & 0.004 \\
\hline $0.91(0.77-1.08)$ & $1.16(0.98-1.37)$ & $1.41(1.20-1.66)$ & $1.98(1.55-2.53)$ & $<0.001$ & \\
\hline $0.97(0.86-1.09)$ & $1.06(0.94-1.19)$ & $1.22(1.08-1.37)$ & $2.02(1.69-2.41)$ & $<0.001$ & \\
\hline \multirow[t]{2}{*}{$0.99(0.84-1.16)$} & $1.06(0.90-1.24)$ & $1.10(0.93-1.30)$ & $1.63(1.21-2.19)$ & $<0.001$ & \\
\hline & & & & & 0.13 \\
\hline $0.93(0.81-1.07)$ & $1.06(0.93-1.21)$ & $1.16(1.02-1.33)$ & $1.71(1.38-2.11)$ & $<0.001$ & \\
\hline \multirow[t]{2}{*}{$0.98(0.88-1.09)$} & $1.09(0.99-1.21)$ & $1.29(1.16-1.43)$ & $2.09(1.78-2.46)$ & $<0.001$ & \\
\hline & & & & & $<0.001$ \\
\hline $0.91(0.79-1.04)$ & $0.93(0.81-1.07)$ & $0.94(0.82-1.09)$ & $1.24(0.97-1.60)$ & 0.002 & \\
\hline $1.01(0.85-1.20)$ & $1.28(1.09-1.51)$ & $1.62(1.38-1.90)$ & $2.70(2.13-3.42)$ & $<0.001$ & \\
\hline $0.74(0.49-1.10)$ & $0.74(0.50-1.11)$ & $0.90(0.60-1.34)$ & $1.65(0.90-3.03)$ & $<0.001$ & \\
\hline $0.94(0.75-1.17)$ & $1.12(0.90-1.40)$ & $1.26(1.01-1.57)$ & $2.15(1.57-2.96)$ & $<0.001$ & \\
\hline 221,840 & 209,676 & 250,494 & 85,953 & & \\
\hline 745 & 734 & 926 & 417 & & \\
\hline $1.08(0.98-1.19)$ & $1.10(1.00-1.21)$ & $1.18(1.08-1.29)$ & 1.68 (1.49-1.89) & $<0.001$ & \\
\hline \multirow[t]{2}{*}{$1.07(0.97-1.18)$} & $1.11(1.00-1.22)$ & $1.17(1.07-1.29)$ & $1.65(1.46-1.85)$ & $<0.001$ & \\
\hline & & & & & 0.04 \\
\hline $1.12(0.98-1.30)$ & $1.12(0.97-1.29)$ & $1.25(1.09-1.43)$ & $1.80(1.53-2.12)$ & $<0.001$ & \\
\hline $0.91(0.75-1.11)$ & $0.94(0.77-1.14)$ & $0.95(0.79-1.16)$ & 1.49 (1.16-1.91) & 0.002 & \\
\hline \multirow[t]{2}{*}{$1.21(1.00-1.46)$} & $1.30(1.07-1.58)$ & $1.38(1.14-1.67)$ & $1.60(1.20-2.13)$ & $<0.001$ & \\
\hline & & & & & 0.79 \\
\hline $1.06(0.87-1.28)$ & $1.16(0.96-1.41)$ & $1.24(1.03-1.50)$ & $1.66(1.31-2.11)$ & $<0.001$ & \\
\hline $1.03(0.89-1.19)$ & $1.16(1.01-1.33)$ & $1.19(1.03-1.36)$ & $1.68(1.42-2.00)$ & $<0.001$ & \\
\hline \multirow[t]{2}{*}{$1.15(0.96-1.37)$} & $1.00(0.83-1.21)$ & $1.10(0.93-1.31)$ & $1.56(1.24-1.97)$ & 0.002 & \\
\hline & & & & & 0.39 \\
\hline $1.03(0.86-1.22)$ & $1.04(0.87-1.24)$ & $1.10(0.93-1.30)$ & $1.62(1.32-1.98)$ & $<0.001$ & \\
\hline \multirow[t]{2}{*}{$1.09(0.97-1.23)$} & $1.13(1.01-1.28)$ & $1.21(1.08-1.35)$ & $1.66(1.43-1.92)$ & $<0.001$ & \\
\hline & & & & & $<0.001$ \\
\hline $1.06(0.91-1.23)$ & $1.21(1.05-1.40)$ & $1.12(0.97-1.29)$ & $1.38(1.14-1.68)$ & 0.002 & \\
\hline $1.15(0.92-1.43)$ & $1.24(1.01-1.54)$ & $1.31(1.07-1.61)$ & $2.27(1.78-2.90)$ & $<0.001$ & \\
\hline $1.29(0.80-2.09)$ & $0.83(0.48-1.44)$ & $1.18(0.73-1.91)$ & $1.57(0.83-2.95)$ & $<0.001$ & \\
\hline $1.13(0.87-1.46)$ & $0.95(0.72-1.26)$ & $1.35(1.05-1.73)$ & $1.79(1.30-2.46)$ & $<0.001$ & \\
\hline
\end{tabular}

9 Multivariable adjusted models were based on the crude model with additional adjustment for smoking status (never smoked, former smoker [stopped $\geq 10$ or $<10$ years ago or time since stopping unknown], current smoker [ $<15,15$ to 24 , or $\geq 25$ cigarettes per day or number unknown], or data missing), educational level (no school degree, primary-school degree, technical- or professional-school degree, secondary-school degree, university degree, or data missing), alcohol consumption (none, 0.1 to 4.9, 5.0 to $14.9,15.0$ to 29.9, or $\geq 30$ g per day), activity (inactive, moderately inactive, moderately active, active, or data missing), and height (in quintiles). All covariates were entered into the models with the use of dummy coding.

$\|$ Relative risks in strata of smoking status were not adjusted for smoking status.

:*: Follow-up of 5 years or less indicates that follow-up time for all participants was censored after 5 years (i.e., only deaths occurring during the first 5 years were considered). Follow-up of more than 5 years indicates that person-time and incident events from the first 5 years of followup were excluded (i.e., only deaths that occurred after more than 5 years of follow-up were included).

The New England Journal of Medicine 


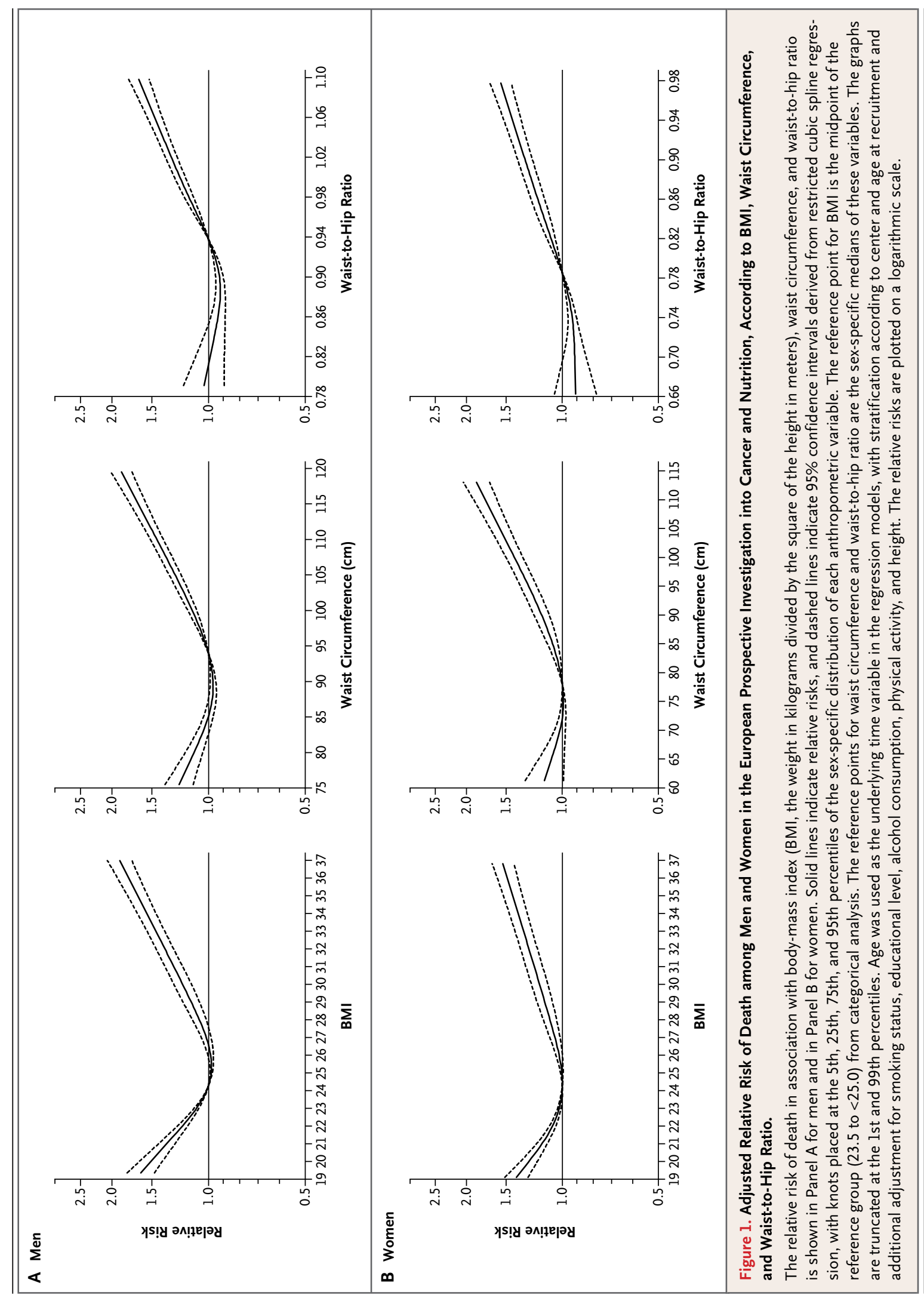


associations were slightly but significantly stronger among men than among women $(\mathrm{P}=0.001$ for an interaction). When not adjusted for BMI, waist circumference and waist-to-hip ratio were significantly associated with the risk of death, with patterns similar to those observed for BMI (Fig. 1 and Table 2, and Table 3 in the Supplementary Appendix).

After further adjustment for BMI, waist circumference and waist-to-hip ratio showed a strong positive association with the risk of death (Table 2 and Fig. 2, and Table 3 in the Supplementary Appendix). For a given BMI in men and women, a waist circumference that was $5 \mathrm{~cm}$ larger was associated with a risk of death that was increased by a factor of 1.17 (95\% confidence interval [CI], 1.15 to 1.20 ) among men and by a factor of 1.13 ( $95 \%$ CI, 1.11 to 1.15$)$ among women $(\mathrm{P}=0.24$ for the difference between men and women), and a waist-to-hip ratio that was 0.1 unit higher was associated with a risk that was increased by a factor of 1.34 (95\% CI, 1.28 to 1.39) among men and by a factor of 1.24 (95\% CI, 1.20 to 1.29 ) among women $(\mathrm{P}=0.04$ for the difference between men and women). In models that included waist circumference or waist-to-hip ratio, BMI remained significantly associated with the risk of death $(\mathrm{P}<0.001)$. Hip circumference was not significantly associated with the risk of death after adjustment for BMI (data not shown).

The associations of waist circumference and waist-to-hip ratio with the risk of death tended to be stronger among participants with a lower BMI, as compared with those who had a higher BMI (Table 2, and Table 3 in the Supplementary Appendix). On cross-classification, participants in the lowest third of BMI and the highest quintile of waist circumference or waist-to-hip ratio, as compared with the reference group (participants in the middle third of BMI and the lowest quintile of waist circumference or waist-to-hip ratio), had the highest relative risk of death (Fig. 3). The findings were similar when BMI was instead categorized as 18.5 to less than 25.0, 25.0 to less than 30.0, and 30.0 or greater (Fig. 1 in the Supplementary Appendix), although the ability to estimate relative risk precisely for the cross-classification of waist circumference by BMI was limited. Among men and women of normal weight, the relative risks in the highest quintile of waist circumference as compared with the lowest quintile were 2.06 (95\% CI, 1.32 to 3.20; $\mathrm{P}<0.001$ for trend) and 1.79 (95\% CI, 1.39 to 2.31; $\mathrm{P}<0.001$ for trend), respectively, and the relative risks in the highest quintile of waist-to-hip ratio as compared with the lowest quintile were 1.79 (95\% CI, 1.53 to 2.10; $\mathrm{P}<0.001$ for trend) and 1.53 (95\% CI, 1.34 to 1.75; $\mathrm{P}<0.001$ for trend), respectively.

The addition of waist circumference or waistto-hip ratio to the regression model that included BMI slightly but significantly increased the $\mathrm{C}$ statistic (Table 4 in the Supplementary Appendix). As shown in Table 3, and in Table 5 in the Supplementary Appendix, despite general agreement among the three regression models across the subject classifications (kappa values, 0.83 to 0.87 ), predicted risk categories changed substantially, and the model estimated the 5-year risk of death more accurately with the addition of waist circumference or waist-to-hip ratio than without these variables for men who had an absolute risk of $2.5 \%$ or greater and for women who had a risk of $1.25 \%$ or greater. The net reclassification index (which indicates the correct movement of participants across predefined risk categories, and thus depends on the choice of risk categories ${ }^{31}$ ) was significant only for the addition of waist-to-hip ratio to BMI among women. However, the integrated discrimination index (which does not depend on the choice of risk categories ${ }^{31}$ ) was highly significant for the addition of waist circumference or waist-to-hip ratio to BMI among participants of both sexes (Table 4 in the Supplementary Appendix).

\section{SUBGROUP ANALYSES}

In subgroup analyses, the relative risk of death associated with a high BMI as compared with reference BMI levels was higher among participants who had never smoked than among former or current smokers, whereas the relative risk at low as compared with reference BMI levels was higher among former and current smokers (Table 1). Among participants who had never smoked, the risk of death was lowest at a BMI of 24.5 for men and 23.9 for women (Fig. 2 and 3 in the Supplementary Appendix). Associations of waist circumference and waist-to-hip ratio with the risk of death tended to be slightly stronger among current smokers than among those who had never smoked, although the test for an interaction was significant for waist circumference only among men (Table 2, and Table 3 in the Supplementary Appendix). When participants were cross- 


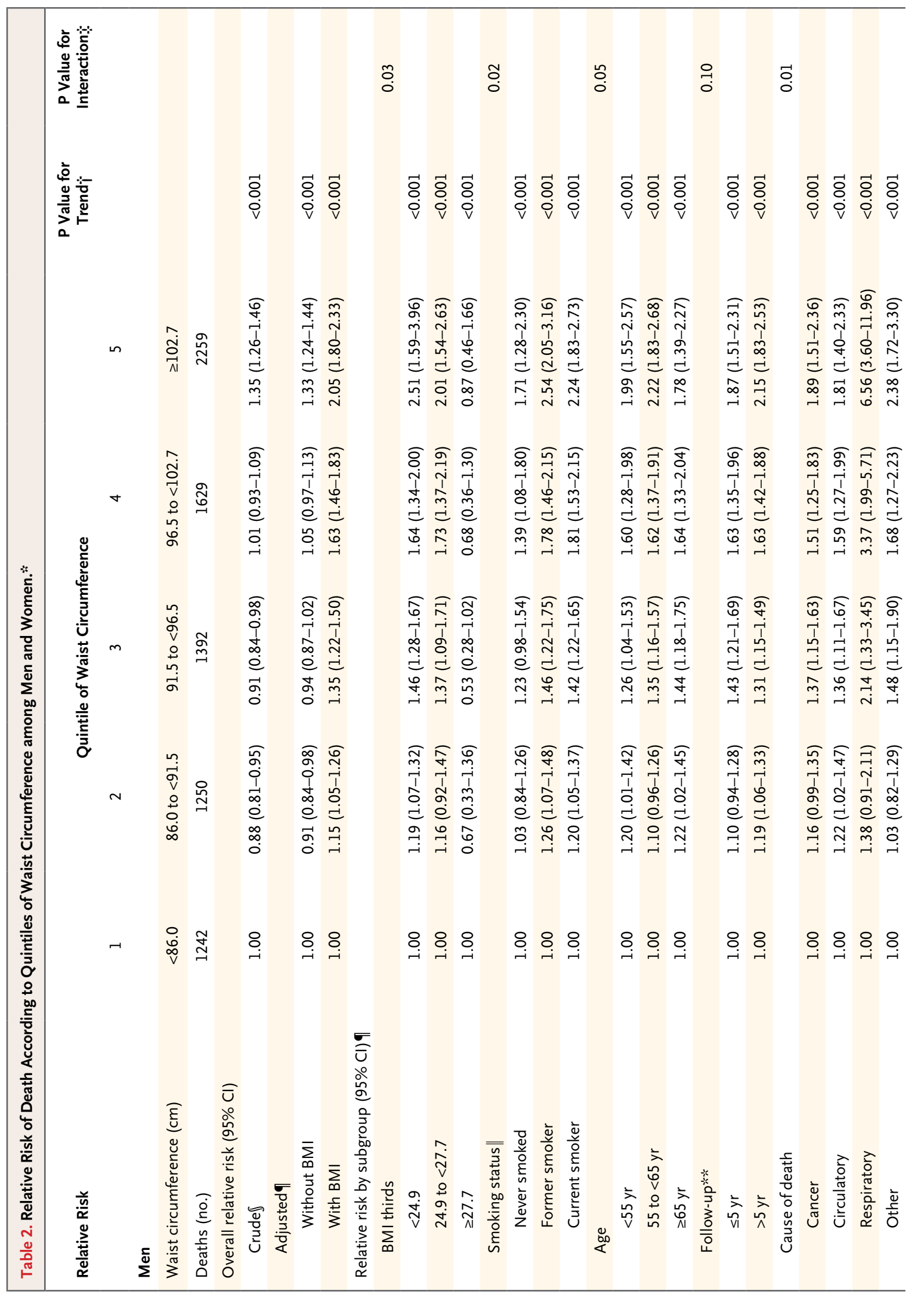




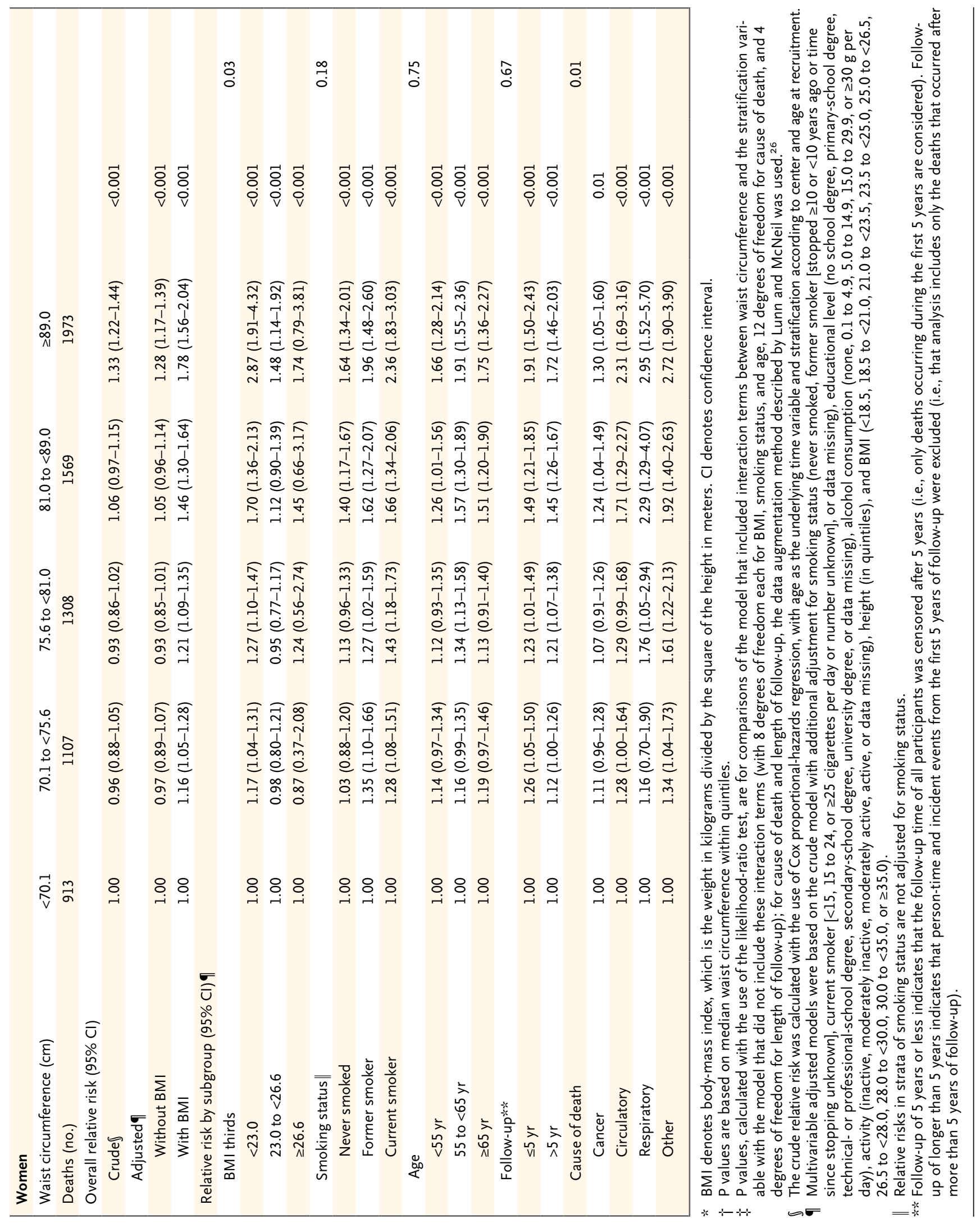




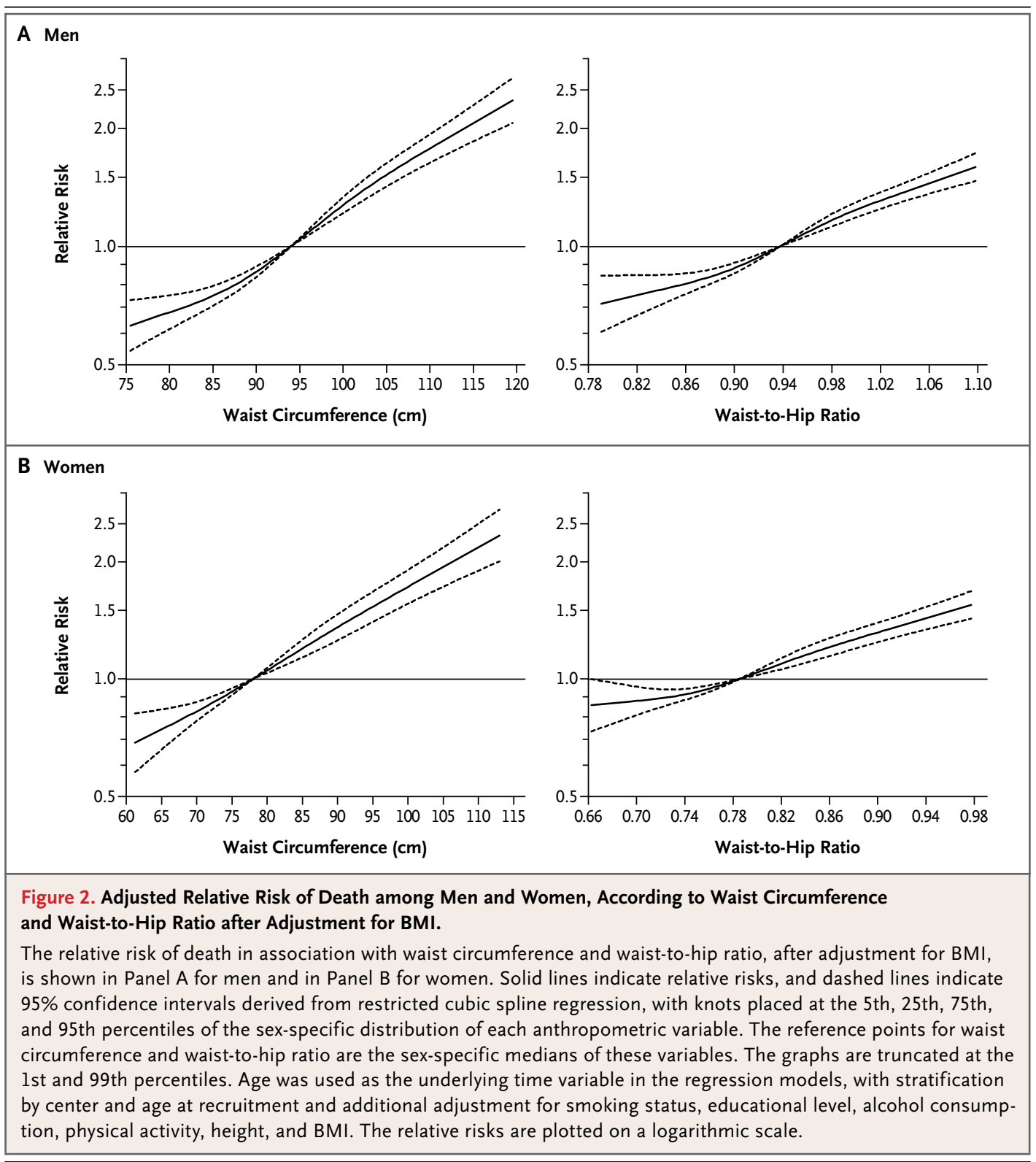

classified, the associations within the group of participants who had never smoked were similar to those reported for the entire cohort (Fig. 4 in the Supplementary Appendix). The association of a high BMI with an increased risk of death was stronger among younger men than among older men, and the association of general and abdominal adiposity with the risk of death among men tended to be stronger for deaths occurring more than 5 years after enrollment than for deaths occurring earlier. The relative risks of death associated with a high BMI were strongest for circulatory causes of death, followed by other causes and neoplasms, whereas the relative risks associated with a high waist circumference or waist-tohip ratio were strongest for respiratory causes of death, followed by other causes (Tables 1 and 2; and Tables 3, 6, 7, and 8 and Fig. 5 in the Supplementary Appendix).

We observed significant heterogeneity across centers among men but not among women for the association of BMI and of waist circumference with the risk of death $(\mathrm{P}=0.001$ for $\mathrm{BMI}$ and $\mathrm{P}=0.004$ for waist circumference). This heterogeneity was driven primarily by the center in Greece, in which associations were weaker than those for 


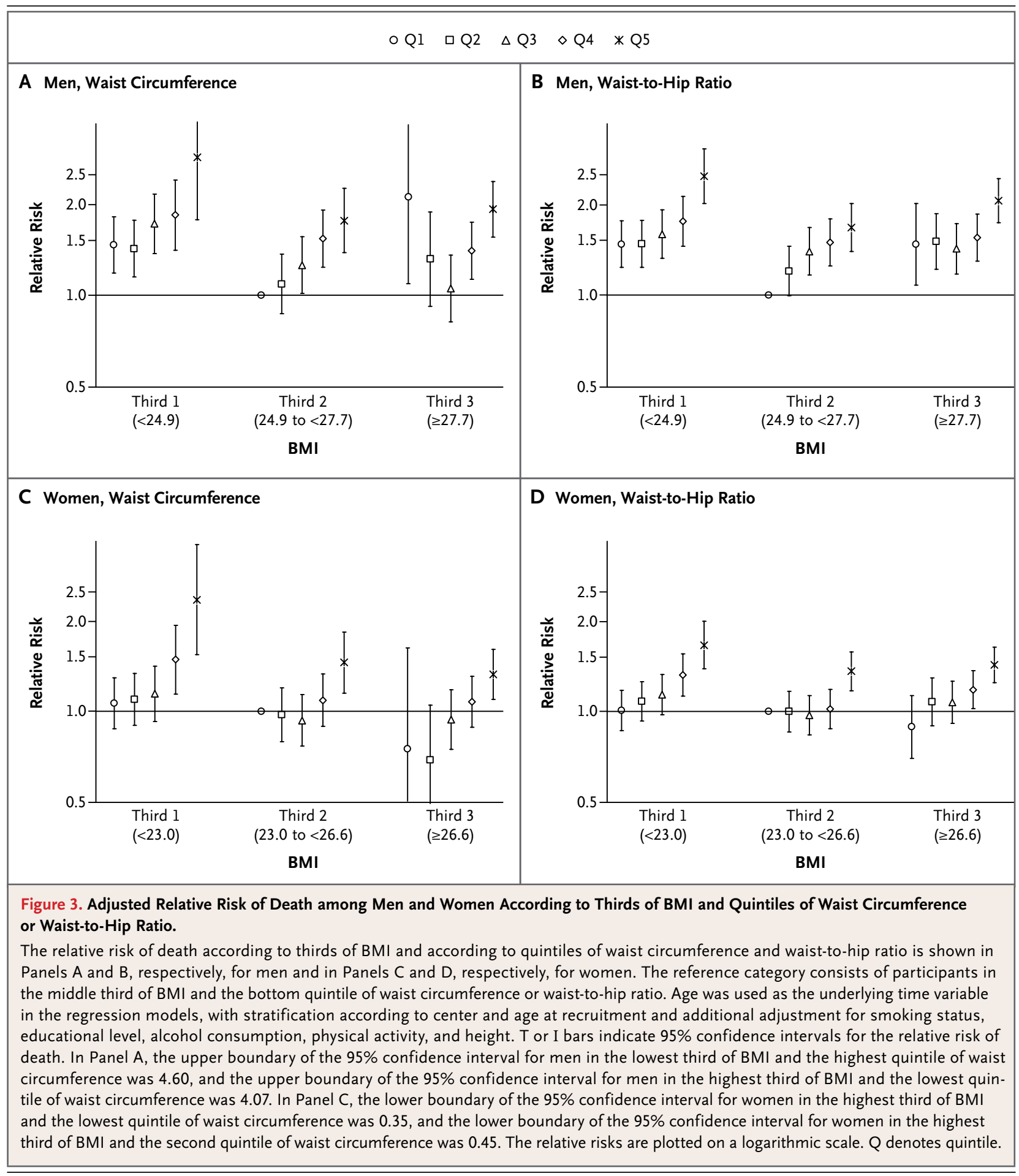

the overall cohort. When the Greek center was excluded, the tests for heterogeneity were no longer significant $(\mathrm{P}>0.05)$, but the overall estimates of relative risk did not change substantially. When we performed sensitivity analyses in which we added the EPIC participants who had been excluded from our main study because their anthropometric measures were based only on selfreport, the overall relative risks did not change appreciably. 


\begin{tabular}{|c|c|c|c|c|c|}
\hline \multirow{3}{*}{$\begin{array}{l}\text { 5-Year Risk According to Model with BMI } \\
\text { Men } \\
<2.5 \%\end{array}$} & \multicolumn{4}{|c|}{$\begin{array}{l}\text { 5-Year Risk According to Model } \\
\text { with BMI and Waist Circumference }\end{array}$} & \multirow[t]{3}{*}{$\begin{array}{c}\text { Total } \\
\text { Reclassified }\end{array}$} \\
\hline & \multirow{2}{*}{$<2.5 \%$} & \multirow[t]{2}{*}{2.5 to $<5.0 \%$} & \multirow[t]{2}{*}{5.0 to $<7.5 \%$} & \multirow[t]{2}{*}{$\geq 7.5 \%$} & \\
\hline & & & & & \\
\hline Total participants (no.) & 86,057 & 1,812 & 0 & 0 & \\
\hline $\begin{array}{l}\text { Participants classified in each stratum according to model } \\
\text { with BMI and waist circumference (\%) }\end{array}$ & 97.94 & 2.06 & 0 & 0 & 2.06 \\
\hline Observed 5-yr risk (\%) & 0.92 & 2.37 & - & - & \\
\hline \multicolumn{6}{|l|}{2.5 to $<5.0 \%$} \\
\hline Total participants (no.) & 1,943 & 17,403 & 950 & 1 & \\
\hline $\begin{array}{l}\text { Participants classified in each stratum according to model } \\
\text { with BMI and waist circumference (\%) }\end{array}$ & 9.57 & 85.74 & 4.68 & 0 & 14.25 \\
\hline Observed 5-yr risk (\%) & 2.16 & 3.49 & 5.47 & 0 & \\
\hline \multicolumn{6}{|l|}{5.0 to $<7.5 \%$} \\
\hline Total participants (no.) & 0 & 892 & 4,998 & 577 & \\
\hline $\begin{array}{l}\text { Participants classified in each stratum according to model } \\
\text { with BMI and waist circumference (\%) }\end{array}$ & 0 & 13.79 & 77.28 & 8.92 & 22.71 \\
\hline Observed 5-yr risk (\%) & - & 4.71 & 6.98 & 7.80 & \\
\hline \multicolumn{6}{|l|}{$\geq 7.5 \%$} \\
\hline Total participants (no.) & 0 & 2 & 563 & 5,640 & \\
\hline $\begin{array}{l}\text { Participants classified in each stratum according to model } \\
\text { with BMI and waist circumference (\%) }\end{array}$ & 0 & 0.03 & 9.07 & 90.89 & 9.10 \\
\hline Observed 5-yr risk (\%) & - & 0 & 7.82 & 14.22 & \\
\hline Women & $<1.25 \%$ & 1.25 to $<2.50 \%$ & 2.50 to $<3.75 \%$ & $\geq 3.75 \%$ & \\
\hline \multicolumn{6}{|l|}{$<1.25 \%$} \\
\hline Total participants (no.) & 179,814 & 3,227 & 0 & 0 & \\
\hline $\begin{array}{l}\text { Participants classified in each stratum according to model } \\
\text { with BMI and waist circumference (\%) }\end{array}$ & 98.24 & 1.76 & 0 & 0 & 1.76 \\
\hline Observed 5-yr risk (\%) & 0.41 & 1.46 & - & - & \\
\hline \multicolumn{6}{|l|}{1.25 to $<2.50 \%$} \\
\hline Total participants (no.) & 2,933 & 25,996 & 1,497 & 6 & \\
\hline $\begin{array}{l}\text { Participants classified in each stratum according to model } \\
\text { with BMI and waist circumference (\%) }\end{array}$ & 9.64 & 85.42 & 4.92 & 0.02 & 14.58 \\
\hline Observed 5-yr risk (\%) & 1.23 & 1.74 & 2.00 & 0 & \\
\hline \multicolumn{6}{|l|}{2.50 to $<3.75 \%$} \\
\hline Total participants (no.) & 0 & 1,457 & 7,053 & 898 & \\
\hline $\begin{array}{l}\text { Participants classified in each stratum according to model } \\
\text { with BMI and waist circumference (\%) }\end{array}$ & 0 & 15.49 & 74.97 & 9.55 & 25.04 \\
\hline Observed 5-yr risk (\%) & - & 1.85 & 2.91 & 3.67 & \\
\hline \multicolumn{6}{|l|}{$\geq 3.75 \%$} \\
\hline Total participants (no.) & 0 & 4 & 864 & 8,334 & \\
\hline $\begin{array}{l}\text { Participants classified in each stratum according to model } \\
\text { with BMI and waist circumference (\%) }\end{array}$ & 0 & 0.04 & 9.39 & 90.57 & 9.43 \\
\hline Observed 5-yr risk (\%) & - & 0 & 3.36 & 6.89 & \\
\hline
\end{tabular}

* The multivariable logistic model included age (in 5-year categories), center, smoking status (never smoked, former smoker [stopped $\geq 10$ or $<10$ years ago or time since stopping unknown], current smoker [ $<15,15$ to 24 , or $\geq 25$ cigarettes per day or number unknown], or data missing), educational level (no school degree, primary-school degree, technical- or professional-school degree, secondary-school degree, university degree, or data missing) alcohol consumption (none, 0.1 to $4.9,5.0$ to $14.9,15.0$ to 29.9 , or $\geq 30 \mathrm{~g}$ per day), activity (inactive, moderately inactive, moderately active, active, or data missing), height (in quintiles), and BMI $(<18.5,18.5$ to $<21.0,21.0$ to $<23.5,23.5$ to $<25.0,25.0$ to $<26.5,26.5$ to $<28.0,28.0$ to $<30.0,30.0$ to $<35.0$, or $\geq 35.0$ ). 


\section{DISCUSSION}

In this large European cohort study, general and abdominal adiposity were independently related to the risk of death. The associations of BMI with the risk of death were J-shaped, with higher risks of death observed in the lower and upper BMI categories than in the middle categories. In contrast, once general adiposity was adjusted for, abdominal fat distribution was positively associated with the risk of death. These associations tended to be stronger among participants with a lower BMI than among those with a higher BMI. Thus, measurement of both general and abdominal adiposity provides a better assessment of the risk of death, particularly among people with a lower BMI.

The most appropriate adiposity markers for assessing the risk of disease and death are debated.4,32 Waist circumference and BMI are highly correlated and when considered individually reflect the extent of both abdominal and general obesity. However, the large sample in our study enabled us to estimate with sufficient precision the effect of abdominal adiposity on the risk of death independently of general obesity. The waistto-hip ratio is less strongly related to BMI than is waist circumference and is therefore a more specific surrogate for fat distribution. Although the waist-to-hip ratio may therefore be preferred as a predictor of the risk of death, in addition to BMI, because it has less potential for collinearity, the use of waist circumference has been predominantly proposed in the past decade, largely because waist circumference is easier to measure and to interpret than the waist-to-hip ratio. ${ }^{2,33}$

The current results underscore the importance of assessing the distribution of body fat even among persons of normal weight and challenge the use of cutoff points to define abdominal obesity, at least when they are used to predict the risk of death. ${ }^{2,34}$ Our finding of a positive association between waist circumference and the risk of death among participants of normal weight may also explain why studies have been unable to show a linear relationship between BMI and the risk of death across the entire range of BMI values.

Like previous studies, our study showed that general obesity was more strongly related to the risk of death among participants who had never smoked, whereas underweight was more strongly related to the risk of death among current smok- ers; these results may reflect the finding that smokers have a lower body weight but a higher risk of death than nonsmokers. ${ }^{15,17,35}$ In contrast, after adjustment for BMI, the association of waist circumference with the risk of death was stronger among smokers. Smokers tend to have a metabolically more adverse fat-distribution profile, with higher central adiposity, than nonsmokers. ${ }^{36}$ Older persons may be more likely than younger persons to have underlying but undiagnosed chronic diseases that are related to a lower BMI and an increased risk of death. Obesity appeared to be more strongly related to the risk of death among younger men than among older men, whereas no such difference was observed among women. The reasons for these sex differences are unclear and may reflect biologic factors or the play of chance. It is also important to note that the absolute risk of death in the reference category varied across subgroups. For example, although general adiposity was more strongly related to the risk of death among people who had never smoked than among current smokers, the absolute risk of death was higher among current smokers (data not shown).

Adipose tissue, particularly tissue from visceral-fat deposits, secretes potential mediators in the development of chronic diseases ${ }^{1}$; this process may explain why abdominal fat distribution was related to the risk of death independently of BMI. Body mass is more closely related to the amount of visceral fat in men than in women, ${ }^{37}$ which may be among the reasons that the relative risk of death among participants with a high BMI was higher for men than for women. The increased risk of death among participants with a low BMI could be the result of low muscle mass, since even at a low BMI, waist circumference was positively related to the risk of death. As in the present study, a recent report suggested that the increase in the risk of death associated with a low BMI is driven primarily by respiratory and other causes, whereas the increased risk associated with a high BMI is driven by cardiovascular causes and cancer. ${ }^{18}$ Although abdominal adiposity is related to chronic inflammation, which may lead to the development of chronic bronchitis and other diseases, the mechanisms for the strong positive associations with deaths from respiratory and other causes are unclear. ${ }^{38}$

Our study has certain limitations. Although people who had a history of cancer, heart dis- 
ease, or stroke were excluded, our analysis may have included a number of participants who had other serious diseases that could potentially confound the observed associations. Nevertheless, we believe that the number of participants with other serious diseases at baseline was small because it is unlikely that such persons would decide to participate in a long-term cohort study. This assumption is indirectly supported by the low prevalence of cancer, heart disease, and stroke in the original EPIC study population. The association of adiposity with the risk of death may vary with a longer follow-up period; however, it would probably become stronger, as suggested by our sensitivity analysis.

The improvement in the prediction of risk by the addition of waist circumference or waist-tohip ratio to BMI was small with respect to the $\mathrm{C}$ statistic, as would be expected, since the C statistic is very insensitive to the detection of true predictors. ${ }^{30,39}$ In contrast, and clinically more important, ${ }^{30}$ the addition of waist circumference or waist-to-hip ratio to BMI more accurately stratified participants into higher-risk and lowerrisk categories.

The causes of heterogeneity across centers, driven by the Greek cohort, are unclear and may reflect differences in the way in which anthropometric measurements were performed, biologic diversity among different populations, or the play of chance. Nevertheless, the relative-risk estimates for the overall cohort did not change substantially when the participants from Greece were excluded from the analysis.

The use of overall mortality and broad categories of cause-specific mortality in our analysis of risk may limit interpretations of the causes of the associations. Nevertheless, such research is crucial for estimating whether reductions in the prevalence of adiposity would affect a population's mortality. Although the level of accuracy for the coding of deaths from cancer and circulatory causes on the basis of information from death certificates is high, it may be lower for the coding of deaths from respiratory causes ${ }^{40}$ Therefore, the analyses according to the cause of death have to be interpreted cautiously. In addition, imperfect follow-up procedures may have resulted in the erroneous classification of some deceased participants as alive. However, we believe that this number was negligibly small, and, given the large sample, the reduction in sensitivity would have no substantial effect on the estimates of relative risk. Finally, although we adjusted our analyses for several variables, because of the observational nature of the study, we cannot exclude the possibility of residual confounding.

In conclusion, the findings of our study suggest that general and abdominal adiposity are both associated with the risk of death. The results support the use of waist circumference or waist-to-hip ratio in addition to BMI in the assessment of the risk of death, particularly among persons with a low BMI.

Supported by grants from the European Commission: Public Health and Consumer Protection Directorate 1993-2004; Research Directorate-General 2005-present; Deutsche Krebshilfe; German Cancer Research Center; German Federal Ministry of Education and Research; Danish Cancer Society; Health Research Fund of the Spanish Ministry of Health (Network of Centers of Research in Epidemiology and Public Health C03/09); the Spanish Regional Governments of Andalucia, Asturia, Basque Country, Murcia, and Navarra; Cancer Research UK; Medical Research Council, United Kingdom; the Stroke Association, United Kingdom; British Heart Foundation; Department of Health, United Kingdom; Food Standards Agency, United Kingdom; the Wellcome Trust, United Kingdom; Greek Ministry of Health and Social Solidarity and Hellenic Health Foundation; Greek Ministry of Education; Italian Association for Research on Cancer; Dutch Ministry of Public Health, Welfare, and Sports; National Cancer Registry and the Regional Cancer Registries Amsterdam, East, and Maastricht of the Netherlands; World Cancer Research Fund; Swedish Cancer Society; Swedish Scientific Council; Regional Government of Skåne, Sweden; French League Against Cancer; the 3M Company; Mutuelle Générale de l'Education Nationale, France; Institut Gustave Roussy, France; and Institut National de la Santé et de la Recherche Médicale, France.

No potential conflict of interest relevant to this article was reported.

This article is dedicated to Dr. Kurt Hoffmann, a key contributor to the manuscript, who died shortly after its finalization.

We thank Bertrand Hemon, Ellen Kohlsdorf, and Wolfgang Bernigau for data coding and all the participants in EPIC for their invaluable contribution to the study.

\section{APPENDIX}

From the Department of Epidemiology, German Institute of Human Nutrition, Potsdam-Rehbruecke, Germany (T.P., H.B., K.H., M.B., M.B.S.); the Departments of Clinical Epidemiology (K.O., M.K.J.) and Cardiology (K.O., J.S.), Aalborg Hospital, Aarhus University Hospital System, Aalborg, Denmark; the Julius Center for Health Sciences and Primary Care, University Medical Center Utrecht, Utrecht, the Netherlands (Y.T.S., K.G.M.M., P.H.M.P., A.M.M.); the Cancer Research UK Epidemiology Unit, University of Oxford, Oxford, United Kingdom (E.S., T.K.); the Danish Cancer Society, Institute of Cancer Epidemiology, Copenhagen (A.T., J.H.); INSERM, ERI 20, EA 4045, and Institut Gustave Roussy, Villejuif, France (F.C.-C., M.-C.B.-R., V.C.); the Division of Clinical Epidemiology, German Cancer Research Center, Heidelberg, Germany (J.L., R.K.); the Department of Hygiene and Epidemiology, University of Athens Medical 
School, Athens (A.T., C.B.); the Department of Epidemiology, Harvard School of Public Health, Boston, and the Hellenic Health Foundation, Athens (D.T.); the Nutritional Epidemiology Unit, National Cancer Institute, Milan (S.S.); the Molecular and Nutritional Epidemiology Unit, Cancer Research and Prevention Institute, Florence, Italy (D.P.); the Cancer Registry, Azienda Ospedaliera Civile M.P. Arezzo, Ragusa, Italy (R.T.); Imperial College London, London, and University of Turin, Turin, Italy (P.V.); Dipartimento di Medicina Clinica e Sperimentale, Università di Napoli, Naples, Italy (S.P.); the Center for Nutrition and Health, National Institute of Public Health and the Environment (RIVM), Bilthoven, the Netherlands (H.B.B.-M., F.J.B.D.); the Department of Public Health and Clinical Medicine, Umeå University, Umeå, Sweden (G.H., L.W.); the Departments of Surgery (J.M.) and Clinical Sciences (B.H.), Malmö University Hospital, Malmö, Sweden; the Institute of Community Medicine, University of Troms $\phi$, Troms $\phi$, Norway (E.L.); the Unit of Nutrition, Environment, and Cancer, Cancer Epidemiology Research Program, Catalan Institute of Oncology, Barcelona (A.A.); the Public Health Department of Gipuzkoa, San Sebastian, Spain (L.A.); the Public Health Institute of Navarra, Pamplona, Spain (A.B.); the Epidemiology Department, Murcia Health Council, Murcia, Spain, and Centro de Investigación Biomédica en Red (CIBER) en Epidemiología y Salud Pública, Barcelona (C.N.); Escuela Andaluza de Salud Publica, Granada, Spain (C.M.); the Health Information Unit, Public Health and Health Planning Directorate, Asturias, Spain (J.R.Q.); Centre for Nutrition and Cancer (S.B.), and the Clinical Gerontology Unit (K.T.K.), University of Cambridge, Cambridge, United Kingdom; the International Agency for Research on Cancer, World Health Organization, Lyon, France (P.B., M.J., P.F.); and the Department of Epidemiology and Public Health, Imperial College London, London (E.R.).

REFERENCES

1. Haslam DW, James WP. Obesity. Lancet 2005;366:1197-209.

2. Expert Panel on the Identification Evaluation and Treatment of Overweight and Obesity in Adults. Executive summary of the clinical guidelines on the identification, evaluation, and treatment of overweight and obesity in adults. Arch Intern Med 1998;158:1855-67.

3. Wang Y, Rimm EB, Stampfer MJ, Willett WC, Hu FB. Comparison of abdominal adiposity and overall obesity in predicting risk of type 2 diabetes among men. Am J Clin Nutr 2005;81:555-63.

4. Yusuf S, Hawken S, Ounpuu S, et al. Obesity and the risk of myocardial infarction in 27,000 participants from 52 countries: a case-control study. Lancet 2005; 366:1640-9.

5. Folsom AR, Kaye SA, Sellers TA, et al. Body fat distribution and 5-year risk of death in older women. JAMA 1993;269: 483-7. [Erratum, JAMA 1993;269:1254.]

6. Baik I, Ascherio A, Rimm EB, et al. Adiposity and mortality in men. Am J Epidemiol 2000;152:264-71.

7. Folsom AR, Kushi LH, Anderson KE, et al. Associations of general and abdominal obesity with multiple health outcomes in older women: the Iowa Women's Health Study. Arch Intern Med 2000;160:2117-28. 8. Katzmarzyk PT, Craig CL, Bouchard C. Adiposity, adipose tissue distribution and mortality rates in the Canada Fitness Survey follow-up study. Int J Obes Relat Metab Disord 2002;26:1054-9.

9. Kalmijn S, Curb JD, Rodriguez BL Yano K, Abbott RD. The association of body weight and anthropometry with mortality in elderly men: the Honolulu Heart Program. Int J Obes Relat Metab Disord 1999;23:395-402.

10. Simpson JA, MacInnis RJ, Peeters A Hopper JL, Giles GG, English DR. A comparison of adiposity measures as predictors of all-cause mortality: the Melbourne Collaborative Cohort Study. Obesity (Silver Spring) 2007;15:994-1003.

11. Dolan CM, Kraemer H, Browner W, Ensrud K, Kelsey JL. Associations between body composition, anthropometry, and mortality in women aged 65 years and older. Am J Public Health 2007;97:913-8. 12. Hu FB, Willett WC, Li T, Stampfer MJ, Colditz GA, Manson JE. Adiposity as compared with physical activity in predicting mortality among women. N Engl J Med 2004;351:2694-703.

13. Zhang $X$, Shu XO, Yang G, et al. Abdominal adiposity and mortality in Chinese women. Arch Intern Med 2007;167:886-92. 14. Visscher TL, Seidell JC, Molarius A, van der Kuip D, Hofman A, Witteman JC. A comparison of body mass index, waisthip ratio and waist circumference as predictors of all-cause mortality among the elderly: the Rotterdam study. Int J Obes Relat Metab Disord 2001;25:1730-5.

15. Lahmann PH, Lissner L, Gullberg B, Berglund G. A prospective study of adiposity and all-cause mortality: the Malmö Diet and Cancer Study. Obes Res 2002;10: 361-9.

16. Bigaard J, Tjфnneland A, Thomsen BL, Overvad K, Heitmann BL, Sørensen TI. Waist circumference, BMI, smoking, and mortality in middle-aged men and women. Obes Res 2003;11:895-903.

17. Adams KF, Schatzkin A, Harris TB, et al. Overweight, obesity, and mortality in a large prospective cohort of persons 50 to 71 years old. N Engl J Med 2006;355:763-78. 18. Jee SH, Sull JW, Park J, et al. Body-mass index and mortality in Korean men and women. N Engl J Med 2006;355:779-87. 19. Zhang C, Rexrode KM, van Dam RM, Li TY, Hu FB. Abdominal obesity and the risk of all-cause, cardiovascular, and cancer mortality: sixteen years of follow-up in US women. Circulation 2008;117:1658-67.

20. Riboli E, Hunt KJ, Slimani N, et al. European Prospective Investigation into Cancer and Nutrition (EPIC): study populations and data collection. Public Health Nutr 2002;5:1113-24.

21. Riboli E, Kaaks R. The EPIC Project: rationale and study design: European Prospective Investigation into Cancer and $\mathrm{Nu}-$ trition. Int J Epidemiol 1997;26:Suppl 1:S6S14.

22. Friedenreich C, Norat T, Steindorf K, et al. Physical activity and risk of colon and rectal cancers: the European Prospective Investigation into Cancer and Nutrition. Cancer Epidemiol Biomarkers Prev 2006;15:2398-407.

23. Bingham SA, Gill C, Welch A, et al. Comparison of dietary assessment methods in nutritional epidemiology: weighed records v. 24 h recalls, food-frequency questionnaires and estimated-diet records. Br J Nutr 1994;72:619-43.

24. Haftenberger $\mathrm{M}$, Lahmann $\mathrm{PH}$, Panico $S$, et al. Overweight, obesity and fat distribution in 50- to 64-year-old participants in the European Prospective Investigation into Cancer and Nutrition (EPIC). Public Health Nutr 2002;5:1147-62.

25. Durrleman S, Simon R. Flexible regression models with cubic splines. Stat Med 1989;8:551-61.

26. Lunn M, McNeil D. Applying Cox regression to competing risks. Biometrics 1995;51:524-32.

27. Hanley JA, McNeil BJ. The meaning and use of the area under a receiver operating characteristic (ROC) curve. Radiology 1982;143:29-36.

28. Hosmer DW, Lemeshow S. Applied logistic regression. 2nd ed. New York: John Wiley, 2000.

29. Nagelkerke NJD. A note on a general definition of the coefficient of determination. Biometrika 1991;78:691-2.

30. Cook NR. Use and misuse of the receiver operating characteristic curve in risk prediction. Circulation 2007;115:928-35.

31. Pencina MJ, D'Agostino RB, D'Agostino RB Jr, Vasan RS. Evaluating the added predictive ability of a new marker: from area under the ROC curve to reclassification and beyond. Stat Med 2008;27:157-72.

32. Welborn TA, Dhaliwal SS. Preferred clinical measures of central obesity for predicting mortality. Eur J Clin Nutr 2007; 61:1373-9.

33. Hu FB. Obesity and mortality: watch your waist, not just your weight. Arch Intern Med 2007;167:875-6.

34. Obesity: preventing and managing the global epidemic: report of a WHO consultation. World Health Organ Tech Rep Ser 2000;894:1-253. 
35. Calle EE, Thun MJ, Petrelli JM, Rodriguez C, Heath CW Jr. Body-mass index and mortality in a prospective cohort of U.S. adults. N Engl J Med 1999;341:1097-105.

36. Barrett-Connor E, Khaw KT. Cigarette smoking and increased central adiposity. Ann Intern Med 1989;111:783-7.

37. Krotkiewski M, Björntorp P, Sjöstrom

L, Smith U. Impact of obesity on metabo- lism in men and women: importance of regional adipose tissue distribution. J Clin Invest 1983;72:1150-62.

38. Poulain M, Doucet M, Major GC, et al. The effect of obesity on chronic respiratory diseases: pathophysiology and therapeutic strategies. CMAJ 2006;174:1293-

39. Harrell FE Jr, Lee KL, Mark DB. Multi- variable prognostic models: issues in developing models, evaluating assumptions and adequacy, and measuring and reducing errors. Stat Med 1996;15:361-87.

40. Kircher T, Nelson J, Burdo H. The autopsy as a measure of accuracy of the death certificate. N Engl J Med 1985;313:1263-9. Coppright (c) 2008 Massachusetts Medical Society. 